\title{
Transdermal Delivery of Fluconazole B-cyclodextrin Complex Incorporated in Aloe vera Gel for Fungal Therapy: Development, Characterization and in vitro Evaluation
}

\author{
Deepak Aswal, Tanuja Bisht* \\ Department of Pharmacy, Guru Ram Das (PG) IMT, Dehradun, Uttarakhand, INDIA.
}

\begin{abstract}
Aim: The aim of the present investigation was to increase the dissolution rate of Fluconazole by solid dispersion technique and then it was incorporated into the gel for better diffusion profile. Fluconazole, an imidazole derivative, is used for the treatment of various local and systemic fungal infections. Materials and Methods: FTIR reports suggested the compatibility between the drug and the excipients. Among all the twelve solid dispersions formulations (F1-F12) prepared by two different methods, F-3 showed best results which were formulated by solvent evaporation method using $\beta$-cyclodextrin. This optimized formulation was then incorporated into Aloe vera gel and was evaluated for various parameters like drug content, $\mathrm{pH}$, viscosity, spreadability, extrudability, in vitro diffusion study, in vitro release kinetics, antifungal and stability studies. Results: The gel formulation, GF1, exhibit high drug content $(94 \% \pm 1.30)$ and acceptable viscosity value of $9166.97 \pm 491 \mathrm{cps}$. The $\mathrm{pH}$ of the gel formulation was $6.88 \pm 0.07$ and exhibited better extrudability and spreadability. The diffusion rate and antifungal activity of GF1 were compared with the marketed formulation (FLUKIN). The GF1 formulation exhibited a faster diffusion rate i.e., $96.92 \%$ than the marketed formulation i.e. $89.24 \%$. Also, the zone of inhibition by GF1 was of diameter $30 \mathrm{~mm}$ which is again higher than the marketed formulation $(24 \mathrm{~mm})$. Conclusion: Overall, it was observed that dissolution of Fluconazole was enhanced and the Aloe vera gel showed better diffusion profile and antifungal activity.
\end{abstract}

Key words: Fluconazole, $\beta$-cyclodextrin solid dispersion, Solvent evaporation, Aloe vera, PVP, Solubility enhancement, Transdermal delivery.

\section{INTRODUCTION}

Fluconazole, an azole antifungal agent and is derived from synthetic triazoles. ${ }^{1}$ It is widely used as first line agent against various fungal infection like oropharyngeal candidiasis, visceral leishmaniasis, dermatomycosis and vulvovaginal candidiasis. ${ }^{2}$ Fluconazole, depending on its concentration, can be fungistatic or fungicidal. Its mechanism involves inhibition of biosynthesis of ergosterol causing hindrance in maintenance of the integrity of the cytoplasmic membrane of the fungi. ${ }^{3}$ Various adverse effects such as headache, nausea, vomiting and abdominal pain etc are associated with the drug when it is administered either from oral or parenteral route. ${ }^{2}$ It is a white crystalline powder with very slight solubility in water $\left(5 \mathrm{mg} / \mathrm{mL}\right.$ at $\left.37^{\circ} \mathrm{C}\right)$ leading to its lower aqueous solubility which resulted in its reduced systemic absorption. ${ }^{4}$

To overcome the solubility issues of the active pharmaceutical ingredients, various approaches are used among which formulation of solid dispersion is most widely used. In solid dispersion, drug is dispersed in biocompatible and inert matrix. ${ }^{5}$ Solid dispersions is an effective technique which can easily enhance the dissolution rate of
Submission Date: 06-10-2020; Revision Date: 02-12-2020; Accepted Date: 08-02-2021

DOI: 10.5530/ijper.55.1s.38 Correspondence: Mrs. Tanuja Bisht Department of Pharmacy, GRD (PG) IMT, Dehradun-248001, Uttarakhand, INDIA. Phone no: +91 8630850830 Email id: t.bisht16@gmail. com

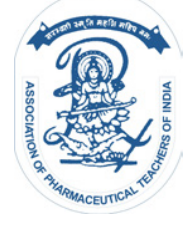

www.ijper.org 
drugs with low aqueous solubility thereby increasing their oral bioavailability also. ${ }^{3}$ Solid dispersions can be formulated using various methods. Among them the most commonly used is Solvent evaporation method which involves dissolution of all components (drug and excipients) in a common volatile solvent followed by evaporation of the solvent. Another widely used method is Hot-melt method in which mixture of drug and carrier is heated to molten state and then immediately cooled to solid state resulting in formation of solid dispersion. ${ }^{5}$ Various polymers such as polyvinyl pyrrolidine, polyethylene glycol, cyclodextrins, mannitol etc are used for the preparation of solid dispersions. In the pharmaceutical field, cyclodextrin and their derivative is becoming polymer of choice due to their potential to form complexes with a variety of drug molecules. ${ }^{6}$ Cyclodextrins (CDs) are a family of cyclic oligosaccharides with a hydrophilic outer surface and a lipophilic central cavity. ${ }^{7}$ They usually form inclusion complexes with various drugs having solubility problems and result in considerable improvement in pharmaceutical properties like solubility, dissolution rate, bioavailability and even many times palatability also without hindering drug's intrinsic lipophilicity and pharmacological properties. Among all three variants of cyclodextrin ( $\alpha, \beta$ and $\gamma$-cyclodextrin), $\beta$-cyclodextrin is the most useful because it can form complexes easily and is cost effective also when compared to other variants. ${ }^{8}$

Fluconazole is used topically to treat various skin diseases. In the present work solid dispersions of Fluconazole are incorporated into Aloe-vera gel which aids in treatment of fungal disease more rapidly. Aloe-vera, A.barbadensis, possesses various therapeutic properties such as antiinflammatory, immunostimulatory, antibacterial, antiviral, anti-fungal and cell growth stimulatory activity. ${ }^{9}$ In many cultures since a very long time, it is used for medical purposes. ${ }^{10-13}$ Recently, Casian has investigated the anti-fungal properties of Aloe vera leaves. ${ }^{14,15}$ The gel has the ability to stimulate cell growth and aids in restoration of damaged skin. Aloe-vera's notable feature is its high water content which ranges from $99.0 \%$ to $99.5 \%$. Due to its high water content and high water holding capacity, it plays important role in keeping the skin moistened. It is reported that Aloe-vera contain more than 75 nutrients and 200 active compounds including anthroquinones, saponins, enzymes, vitamins, lignin, minerals, amino acids, sugar etc. Both the part of Aloevera i.e. outer rind and inner colorless parenchyma gel has their own medicinal values. From the previous studies, it has been reported that Aloe-vera itself also has some antifungal activity. ${ }^{16,17}$
In the present work, the solid dispersions of Fluconazole were formulated using two different polymers by two different methods and were compared on various pharmaceutical factors. The optimized formulation of solid dispersion was incorporated in Aloe-vera gel which is used to synergize the antifungal effect of Fluconazole and also aids in permeation of drug into the skin.

\section{MATERIALS AND METHODS}

Materials used were Fluconazole (Apstech, Roorkee), $\beta$-Cyclodextrin (HiMedia Lab. Pvt. Ltd., Mumbai), PVP (Loba Chemie Pvt. Ltd., India), carbopol 940 and Aloe-vera. All the chemicals used were of AR grade.

\section{Preparation of Fluconazole solid dispersion Preparation of Complex}

\section{Solvent evaporation method}

Accurately weighed amount of Fluconazole and the excipients $(\beta$-Cyclodextrin and PVP) were dissolved in sufficient volume of methanol with continuous stirring. The solvent was then completely evaporated at $40-45^{\circ} \mathrm{C}$ with continuous stirring to obtain dry granules (Table 1). ${ }^{7}$

\section{Hot-melt Method}

Fluconazle along with other excipients were accurately weighed and then were kept at high temperature resulting in melting of both drug and polymer. The molten mixture was then immediately cooled using ice cold water which leads to formation of hard mass. The dried

\begin{tabular}{|c|c|c|c|}
\hline S.No. & Composition & Method & $\begin{array}{c}\text { Ratio } \\
\text { (Drug:Carrier) }\end{array}$ \\
\hline 1. & Drug $+ß$-cyclodextrin & $\begin{array}{c}\text { Solvent } \\
\text { Evaporation }\end{array}$ & $1: 1$ \\
\hline 2. & Drug $+ß$-cyclodextrin & $\begin{array}{c}\text { Solvent } \\
\text { Evaporation }\end{array}$ & $1: 2$ \\
\hline 3. & Drug $+ß$-cyclodextrin & $\begin{array}{c}\text { Solvent } \\
\text { Evaporation }\end{array}$ & $1: 3$ \\
\hline 4. & Drug+PVP* & $\begin{array}{c}\text { Solvent } \\
\text { Evaporation }\end{array}$ & $1: 1$ \\
\hline 5. & Drug+PVP* & $\begin{array}{c}\text { Solvent } \\
\text { Evaporation }\end{array}$ & $1: 2$ \\
\hline 6. & Drug+PVP* & $\begin{array}{c}\text { Solvent } \\
\text { Evaporation }\end{array}$ & $1: 3$ \\
\hline 7. & Drug+ß-cyclodextrin & Hot Melt & $1: 1$ \\
\hline 8. & Drug+ß-cyclodextrin & Hot Melt & $1: 2$ \\
\hline 9. & Drug+ß-cyclodextrin & Hot Melt & $1: 3$ \\
\hline 10. & Drug+PVP* & Hot Melt & $1: 1$ \\
\hline 11. & Drug+PVP* & Hot Melt & $1: 2$ \\
\hline 12. & Drug+PVP* & Hot Melt & $1: 3$ \\
\hline
\end{tabular}

*PVP- Polyvinylpyrrolidine 
mass was pulverized and passed through sieve no. 100 (Table 1). ${ }^{1}$

\section{Evaluation parameters of Fluconazole Solid Dispersion Fourier-transform infra-red spectroscopy (FTIR)}

FTIR of pure drug and physical mixture of drug and excipients were performed using FTIR spectrophotometer (IR Affinity1, Shimadzu, Japan). FTIR was performed with the aim to check the chemical interaction between drug and other excipients used in the formulation. Sample preparation for FTIR is done by using powdered drug and excipients and mixing them with dry potassium bromide intimately. The mixture was kept on diffused reflectance sampler and spectrum was recorded by scanning in wavelength region of $4000-400 \mathrm{~cm}^{-1}$.

\section{Drug Content of Complex}

Weighed amount of solid dispersions equivalent to $10 \mathrm{mg}$ of Fluconazole were taken and was dissolved in ethanol. Further appropriate dilutions were done using Phosphate buffer $\mathrm{pH}$ 6.8. Finally, the absorbance of solutions was determined at $260 \mathrm{~nm}$ by UV-Visible Spectrophotometer.

\section{Solubility studies of Solid Dispersions}

Various formulations of Fluconazole Solid dispersions were taken in beakers filled with required amount of distilled water and then kept in mechanical shaker for $8 \mathrm{hr}$. The solution was then filtered using microfilter and the absorbance of the same was taken at $260 \mathrm{~nm}$ using UV-Visible spectrophotometer.

\section{In vitro Dissolution Study}

Dissolution studies were performed assuring sink condition using USP apparatus type-I (Electrolab TDTO9T). The dissolution medium used for the study was Phosphate buffer $\mathrm{pH} 6.8$ and the temperature was maintained at $37^{\circ} \mathrm{C} \pm 0.5^{\circ} \mathrm{C}$. The solid dispersions containing $50 \mathrm{mg}$ of Fluconazole drug was filled in capsules and then kept in basket of the dissolution apparatus with the rotating speed of $50 \mathrm{rpm}$. Samples were withdrawn at regular interval of $10 \mathrm{~min}$ for $60 \mathrm{~min}$ and were analyzed spectrophotometrically at $260 \mathrm{~nm}$ using UV-visible spectrophotometer. Dissolution of the pure drug was also performed. Each preparation was tested in triplicate. ${ }^{3}$

\section{Incorporation of Solid Dispersion in Aloe-vera Gel Preparation of Aloe-vera Gel \\ Extraction}

The fresh leaves of Aloe vera (Aloe barbadensis) plant were taken from Herbal Garden, GRD (PG) IMT, Dehradun, Uttarakhand. Leaves were then washed in tap water for
15 min and then rinsed with distilled water and mild chlorine solution. The leaves were cut longitudinally and the inner gel-like pulp was removed using a spoon. It is then minced and homogenized in a mixer. ${ }^{14,18,19}$

\section{Formulation of Fluconazole solid dispersion incorporated Aloe vera Gel}

Aloe vera gel is prepared by dissolving glycerin, methyl paraben and propyl paraben in distilled water. Carbopol-940, the gelling agent, is added to the mixture and continuous stirring was done till it got swollen completely. Triethanolamine was added drop wise under continuous stirring till the required consistency is obtained. Finally, Aloe vera extract was added to it and stirred for $15 \mathrm{~min}$. Final volume of the formulation was made up with distilled water under continuous stirring for 15 min till a uniform gel is obtained. ${ }^{14}$ At the end, solid dispersion of Fluconazole equivalent to $1 \mathrm{gm}$ drug is dissolved in ethanol and this dry solution is incorporated in the formulated gel (Table 2). The mixture is properly mixed until a homogenous gel is obtained.

\section{Evaluation of $\mathrm{Gel}$}

\section{Determination of $\mathrm{pH}$}

The $\mathrm{pH}$ of all three formulations was measured using digital $\mathrm{pH}$ meter. An aqueous dispersion of $1 \mathrm{gm}$ Fluconazole Aloe-vera gel was made in $100 \mathrm{~mL}$ distilled water and kept for some time. The $\mathrm{pH}$ meter was calibrated with standard buffer solution of $\mathrm{pH}$ 4.0, 7.4 and 9.0. The measurement of $\mathrm{pH}$ of each formulation was done in triplicate and average values were calculated. ${ }^{10}$

\section{Viscosity Estimation}

The measurement of viscosity of the prepared gel was done with a Brookfield Rheometer. The gels were rotated at $1 \mathrm{rpm}$ and the corresponding dial reading was noted.

\begin{tabular}{|c|c|c|c|c|}
\hline S.No & Ingredients & GF1 & GF2 & GF3 \\
\hline 1 & $\begin{array}{l}\text { Solid dispersion } \\
\text { equivalent to } 1 \mathrm{~g} \text { of } \\
\text { Fluconazole }\end{array}$ & 4.56 & 4.56 & 4.56 \\
\hline 2 & Aloe-vera Gel (g) & 45 & 45 & 45 \\
\hline 3 & Carbopol 940 (g) & 0.25 & 0.50 & 0.75 \\
\hline 3 & Glycerine (\%w/w) & 0.5 & 0.5 & 0.5 \\
\hline 4 & $\begin{array}{c}\text { Methylparaben } \\
(\% \mathrm{w} / \mathrm{w})\end{array}$ & 0.01 & 0.01 & 0.01 \\
\hline 5 & $\begin{array}{c}\text { Propylparaben } \\
(\% \mathrm{w} / \mathrm{w})\end{array}$ & 0.01 & 0.01 & 0.01 \\
\hline 6 & $\begin{array}{l}\text { Triethanolamine } \\
\qquad(\% \mathrm{w} / \mathrm{w})\end{array}$ & 0.2 & 0.2 & 0.2 \\
\hline 7 & Water(ml) & q.s & q.s & q.s \\
\hline
\end{tabular}


The viscosity of the gel was obtained by that reading. The viscosity was measured in cPs. Experiments were carried out in triplicates. ${ }^{10}$

\section{Spreadability}

It is an important criterion for a topical formulation as it describes the ability of the formulation to spread on the area of application. It indicates the extent of area to which the gel quickly spreads when applied to skin or affected area. The therapeutic effectiveness of the gel formulation also depends on its spreading value. Spreadability of the gel was determined by placing $0.5 \mathrm{~g}$ of gel within a circle of $1 \mathrm{~cm}$ diameter pre-marked on a glass plate of $20 \times 20 \mathrm{~cm}$, over which a second glass was placed. A weight of $500 \mathrm{~g}$ was kept on the upper glass plate for $5 \mathrm{~min}$ and the increase in the diameter due to gel spreading was noted. ${ }^{14}$

\section{Extrudability}

The collapsible tube was filled with the formulation and was pressed firmly from the crimped end for the determination of the extrudability of the gel. While the cap was removed, formulation extruded to release the pressure applied. Weight in grams required to extrude a $0.5 \mathrm{~cm}$ ribbon of the formulation in 10 secs was determined. The test was performed in triplicate and the average values were calculated. The extrudability was then calculated by using the following formula.

$$
\begin{aligned}
\text { Extrudability }= & \text { Weight applied to extrude gel from } \\
& \text { tube (in gm) } / \text { Area }\left(\text { in } \mathrm{cm}^{2}\right) .
\end{aligned}
$$

\section{Drug content}

A specific amount of formulated gel was accurately weighed and dissolved in a suitable solvent. The volumetric flask containing gel solution was kept on mechanical shaker for $2 \mathrm{hrs}$ so that the drug gets solubilised completely. The solution was filtered using Milipore filter $(0.45 \mu \mathrm{m})$ and the absorbance was measured spectrophotometrically at $260 \mathrm{~nm}$ after appropriate dilutions. Calculation of the drug content was done using the slope and the intercept obtained by linear regression analysis of standard calibration curve. Experiments were carried out in triplicates.

\section{In vitro Diffusion study}

In the present work, modified Kiescary Chein diffusion cell was used for the diffusion study. Specified amount of Fluconazole gel was accurately weighed and was kept on dialysis membrane in the donor compartment in such a manner that there was complete contact between the entire membrane surface containing formulation and the phosphate buffer $\mathrm{pH} 7.4$ kept in the receiver compartment. This assembly was placed on a magnetic stirrer with continuous stirring at $100 \mathrm{rpm}$, temperature maintained at $37^{\circ} \mathrm{C}$ for a specific time period. The samples were withdrawn from the receptor compartment at regular time interval and sink condition was also maintained. The absorbance of the samples was measured spectrophotometrically at $260 \mathrm{~nm}$ using UV-Visible Spectrophotometer.

\section{Release kinetics of the gel formulation}

To analyze the mechanism for the release and release rate kinetics of the dosage form, the data obtained from the in vitro diffusion study was fitted in to Zero order, First order, Higuchi matrix and Korsmeyer- Peppas model. By comparing the $R^{2}$ values obtained, the best fit model was selected.

\section{Antifungal Study}

Antifungal studies of the prepared formulations were done using Agar cup method against Candida albican strain. Using Sabouraud dextrose agar media, a cupt of $10 \mathrm{~mm}$ in diameter was made aseptically. The tested fungal suspension strain was then spread over the agar surface. The prepared formulations along with the marketed formulation were introduced in each cup using sterile syringe. Finally, the zone of inhibition of each cup was observed and calculated the radius of zone of inhibition and it was compared with the marketed formulation (Flukin, MDC Pharmaceuticals Ltd). ${ }^{20}$

\section{Stability Studies}

The stability studies were carried out for the optimized formulation. The formulation was kept in a plastic box and was sealed and the box was then kept at $25^{\circ} \mathrm{C} \pm 2^{\circ} \mathrm{C}$ and $40{ }^{\circ} \mathrm{C} \pm 2^{\circ} \mathrm{C}$ at $\mathrm{RH} 60 \pm 5 \% \mathrm{RH}$ and $75 \pm 5 \% \mathrm{RH}$ for 3 months. The sample was analyzed for $\mathrm{pH}$, viscosity and in vitro diffusion study at the end of $1^{\text {st }}, 2^{\text {nd }}$ and $3^{\text {rd }}$ month of the study period.

\section{RESULTS}

\section{Preparation of Solid dispersion}

Fluconazole solid dispersion formulations were prepared using two different polymers viz, $\beta$-cyclodextrin and Polyvinylpyrrolidine and all the 12 formulations were prepared using two different methods i.e, Solvent evaporation and Hot melt method.

\section{FTIR Studies}

FTIR studies reveal that there is no change in the drug when it is mixed with the excipients. Figure 1 and Figure 2 showed that the drug is compatible with both $\beta$-cyclodextrin and Polyvinylpyrrolidine. 


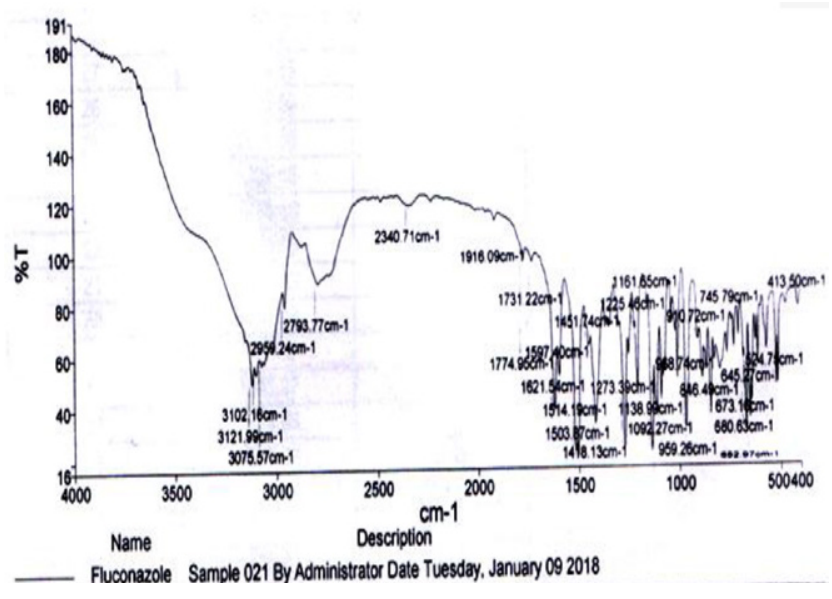

Figure 1: FTIR of Fluconazole drug.

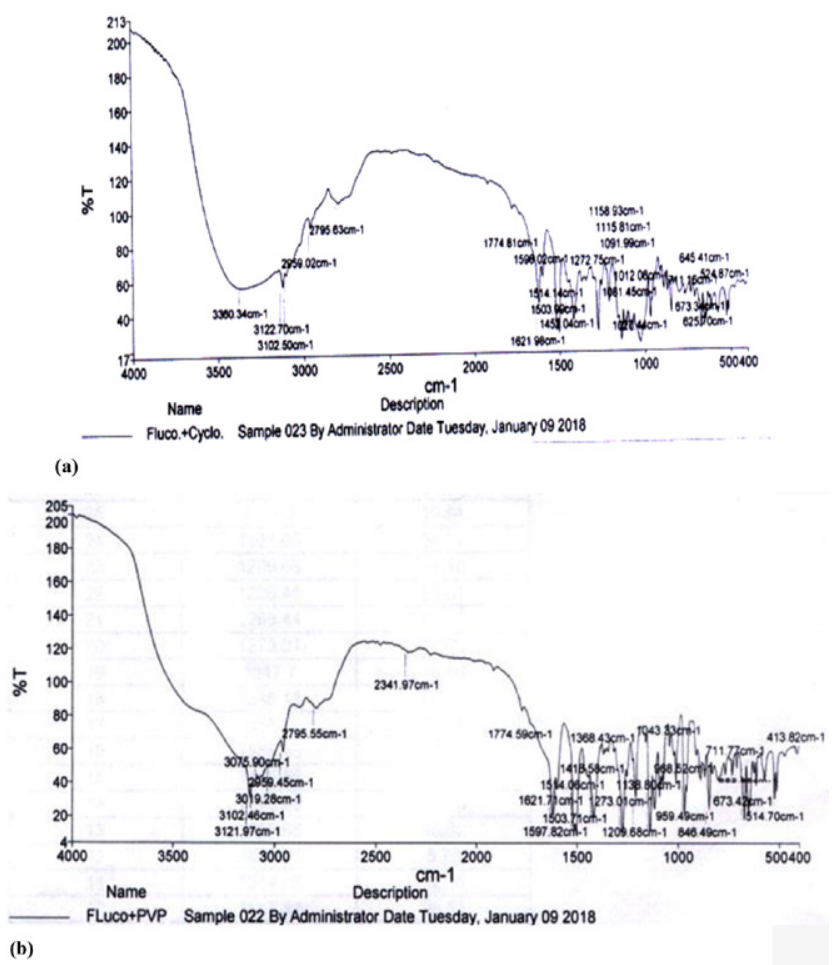

Figure 2: FTIR of (a) Fluconazole and B-cyclodextrin (b) Fluconazole and PVP.

\section{Evaluation of Solid dispersion}

\section{Drug Content}

It can be depicted after the drug content studies of all the 12 formulations that drug content varied from $55.96-87.11 \%$. Among all the formulations, F3 showed highest drug content i.e, $87.11 \%$. This formulation was prepared using solvent evaporation method (Table 3).

\section{Solubility study}

In the present study, it was found that aqueous solubility of the pure drug was $25.63 \%$, which was very low. While the aqueous solubility of the Fluconazole dispersions was found to be in the range of $63.54 \%$ (F-10) to

\begin{tabular}{|c|c|c|}
\hline \multicolumn{2}{|c|}{$\begin{array}{c}\text { Table 3: Percentage drug content and aqueous solu- } \\
\text { bility of fluconazole solid dispersion formulations. }\end{array}$} \\
\hline Formulation & \% Drug Content & \% Aqueous Solubility \\
\hline F1 & 56.25 & 68.31 \\
F2 & 70.82 & 70.52 \\
F3 & 87.11 & 85.46 \\
F4 & 69.91 & 80.22 \\
F5 & 55.96 & 69.61 \\
F6 & 80.45 & 65.52 \\
F7 & 58.53 & 68.26 \\
F8 & 71.25 & 72.71 \\
F9 & 82.32 & 75.30 \\
F10 & 60.28 & 63.54 \\
F11 & 72.53 & 65.05 \\
F12 & 79.62 & 69.31 \\
PURE DRUG & 100 & 25.63 \\
\hline
\end{tabular}

$85.46 \%$ (F-3). From the data shown in Table 3, it can be seen that in both the methods, solid dispersion prepared using $\beta$-cyclodextrin showed greater aqueous solubility rather than solid dispersion using PVP. From the previous studies, it is evident that cyclodextrins increases apparent water solubility as they form non-covalent, water soluble inclusion complexes. ${ }^{21}$ The elevated drug aqueous solubility aids in the better bioavailability and hence increased therapeutic efficacy of the dosage form. ${ }^{22}$ Also in the cyclodextrin inclusion complex there is no covalent bonds are formed or broken and when the complex enters the aqueous solution, dissociation of the complex readily takes place and the drug molecule is free and equilibrium is maintained between free drug molecules and those bound within the cyclodextrin complex. ${ }^{7,23}$

\section{In vitro Dissolution study}

The dissolution studies revealed that solid dispersion dissolution rate was faster than the pure drug (Figure 3). From the Figure 4, it can be seen that values for dissolution rate of all the 12 solid dispersion formulations ranges from $82.41-98.49 \%$ in a time interval of $60 \mathrm{~min}$. The formulation F-3 prepared by solvent evaporation method, showed highest dissolution rate i.e, 98.49\% after 50 min only. Also the formulation F-9 prepared by hot melt method showed highest dissolution rate i.e, $96.87 \%$ after $60 \mathrm{~min}$, among the formulations F-7 to F-12. The increased dissolution rate may be attributed due to the presence of $\beta$-cyclodextrin in the formulation F-3. From the previous studies it is proven that in solid dispersion with $\beta$-cyclodextrin, Fluconazole is present in amorphous form leading to faster dissolution rate. ${ }^{24}$ Furthermore, it is also reported that $\beta$-cyclodextrin 
possess surfactant like properties which results in the reduction of interfacial tension between the water insoluble drug and the dissolution medium, leading to elevated dissolution rate. ${ }^{25,26}$

After evaluation of all the 12 solid dispersion formulations for their drug content, aqueous solubility and in vitro dissolution, the optimized formulation was selected for the incorporation in the Aloe vera gel. It was found that formulation F-3, prepared using solvent evaporation method exhibited highest drug content, solubility and dissolution rate among all the 12 formulations. Hence, further studies were carried out using F-3 formulation.

\section{Evaluation of Fluconazole solid dispersion Aloe vera Gel}

The optimized Solid dispersion formulation i.e, F-3 was incorporated in Aloe-vera gel and three formulations were prepared by varying amount of Aloe-vera in each formulation (GF1, GF2, GF3). Following are the results obtained after the evaluation of the formulated gel preparations.

\section{pH of the gel formulation}

The Aloevera gel formulation GF1 and GF2 was translucent while GF3 was opaque. The $\mathrm{pH}$ of all the formulation was found to be in the range of 6.8-7.01, which is an acceptable range for the topical formulations. (Table 4).

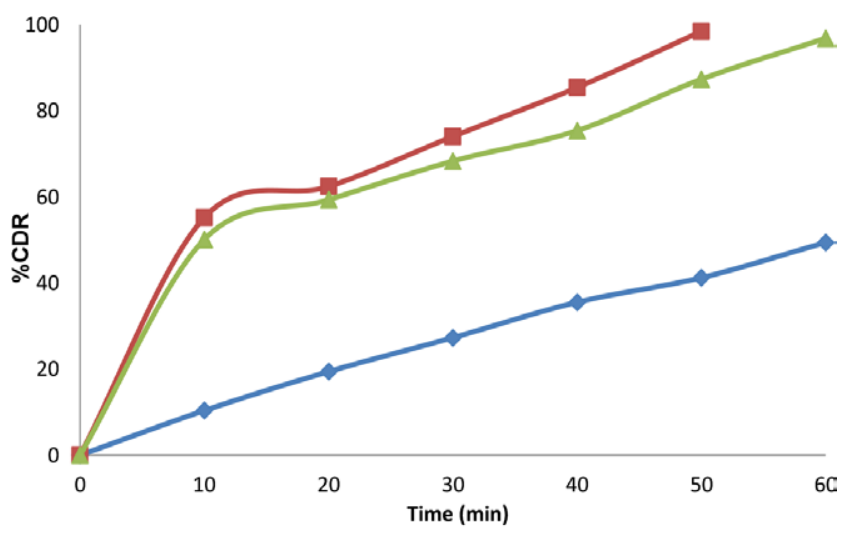

$\longrightarrow$ Pure Drug $\longrightarrow$ F3 $-\mathrm{Fg}$

Figure 3: Comparative dissolution profile of Fluconazole pure drug, F3 and F9.

\section{Viscosity, Spreadability and Extrudability}

Viscosity of the formulated gel was found to be in the acceptable range, data is shown in Table 4. The Spreadability of a gel is an important factor that aids patient compliance and in uniform application of gel on the skin. Gels which can spread easily after application of very small shear force are considered best for the formulation. In the present study, the prepared GF-1 showed spreadability which is acceptable i.e. 6.98 \pm 0.32 , for easy spreading of the gel (Table 4). Extrudability relates to the extent to which a semisolid formulation is extruded out from the tube. The viscosity and consistency of the semisolid preparation affects the extrudability of the formulation. There is inverse relation found between the extrudability and the viscosity i.e, the lesser the viscosity, the more will be the extrudability. Extrudability of all the three formulations was found to be $15.52 \pm 0.09,12.75 \pm 0.10$ and $9.95 \pm 0.45$ (Table 4)..$^{19,27}$

\section{Drug Content}

From the study it was observed that formulation GF1 showed highest drug content i.e, $94 \% \pm 1.30$ followed by GF2 with a value of $91.5 \% \pm 1.65$ while $80.88 \% \pm 1.93$ drug content was found in formulation GF3 (Table 4).

\section{In vitro Diffusion study}

From the Figure 5, it can be seen that the drug release from the gel formulation showed inverse relationship

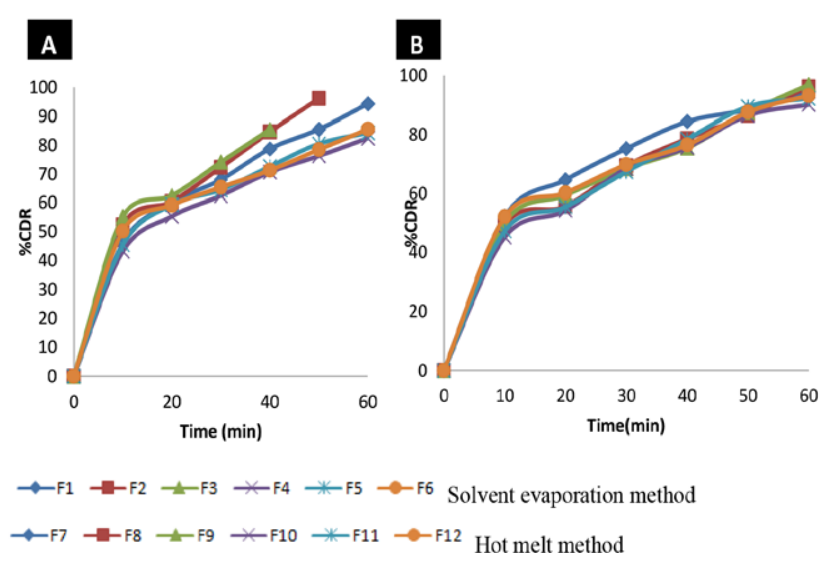

Figure 4: Dissolution profile of Fluconazole solid dispersions formulated by (A) Solvent Evaporation (B) Hot melt Method; All the results are mean $\pm \operatorname{SD}(n=3)$.

Table 4: Evaluation Parameters of Fluconazole Solid Dispersion Incorporated Aloe vera Gel Formulations.

\begin{tabular}{|c|c|c|c|c|c|c|}
\hline Formulation & $\begin{array}{c}\text { Physical } \\
\text { Appearance }\end{array}$ & $\begin{array}{c}\text { Drug content } \\
\text { (\%) }\end{array}$ & pH & $\begin{array}{l}\text { Viscosity } \\
\text { (Cps) }\end{array}$ & $\begin{array}{l}\text { Spreadability } \\
\text { (cm/sec) }\end{array}$ & $\begin{array}{l}\text { Extrudability } \\
\left(\mathrm{gm} / \mathrm{cm}^{2}\right)\end{array}$ \\
\hline GF1 & Translucent & $94 \% \pm 1.30$ & $6.88 \pm 0.07$ & $9166 \pm 491$ & $6.98 \pm 0.32$ & $15.52 \pm 0.09$ \\
\hline GF2 & Translucent & $91.5 \% \pm 1.65$ & $6.93 \pm 0.13$ & $25428 \pm 576$ & $8.01 \pm 0.67$ & $12.75 \pm 0.10$ \\
\hline GF3 & Opaque & $80.88 \pm 1.93$ & $7.01 \pm 0.06$ & $35581 \pm 894$ & $12.76 \pm 0.24$ & $9.95 \pm 0.45$ \\
\hline
\end{tabular}




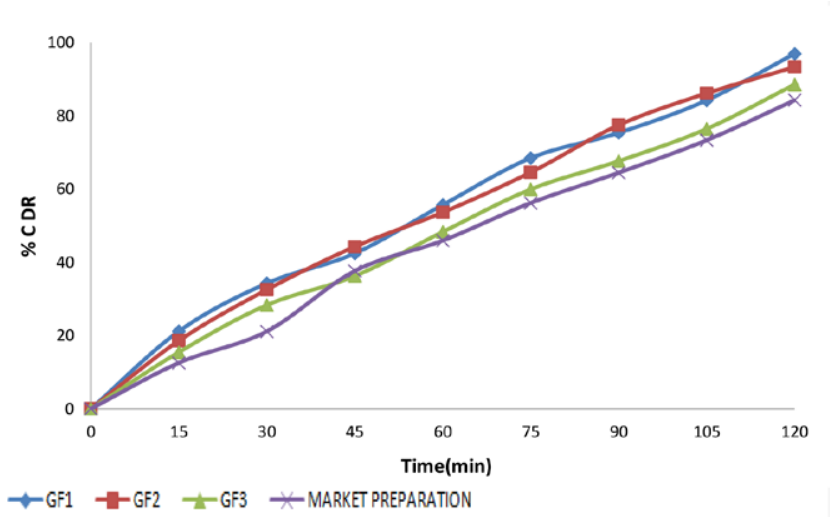

Figure 5: Comparative diffusion profile of Fluconazole SD incorporated gel formulations and marketed gel preparation.

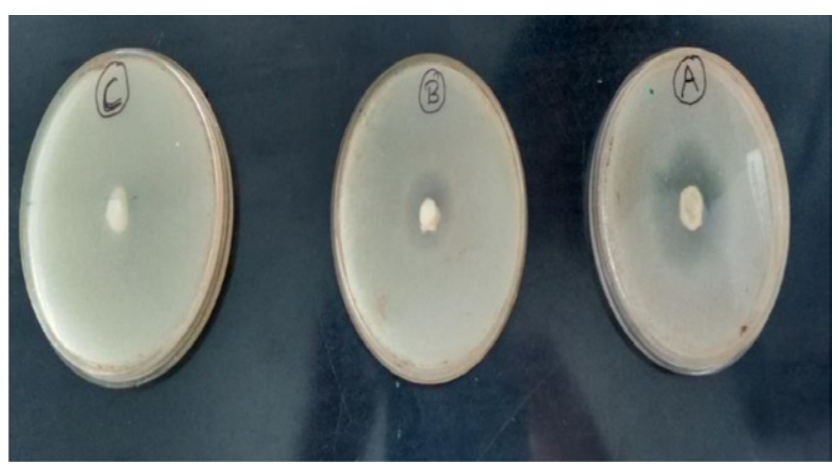

Figure 6: Comparative antifungal study of (a) Optimized gel formulation (b) marketed gel formulation and (c) Placebo.

with the polymer concentration i.e., with the increase in polymer concentration (Carbopol 940) there is reduced drug release from the gel formulation. The crosslink density of the polymer will increase with increase in polymer concentration resulting into high inter-linkage of the polymer molecules from which the drug release occurs within the hydrogel network. After the time interval of $120 \mathrm{~min}$, it was observed that GF1 formulation, having least amount of polymer concentration, showed highest drug release $(96.92 \%)$ which is even greater than the marketed formulation, Flukin (MDC Pharmaceuticals Ltd), which showed $89.24 \%$ drug release after $120 \mathrm{~min}^{28}$

\section{In vitro Release Kinetics}

In order to calculate the release constant and regression coefficients $\left(R^{2}\right)$, the drug release data was fitted in various kinetic models. It was found that GF-1 formulation was best fitted with Korsmeyer Peppas model and showed regression coefficient of 0.9969 . This exhibits that the amount of drug released was dependant on the matrix drug load. The diffusion exponent $(n)$ value obtained was 0.8074 , which is more than 0.5 and thus indicates that the drug release mechanism involved is non-fickian mechanism of drug release.

\section{Anti-fungal Study}

From the Figure 6, it was observed that zone of inhibition made by optimized formulation GF1 $(30 \mathrm{~mm})$, was greater than the marketed formulation (Flukin) (24 $\mathrm{mm})$ and placebo. It can be summarized that antifungal activity of the prepared gel against the selected test organism (Candida albicans) is acceptable and greater than the marketed formulation.

\section{Short-term Stability Studies}

A three-month short term stability study of the optimized formulation was carried out at room and accelerated temperature i.e, $25 \pm 2{ }^{\circ} \mathrm{C} / 60 \pm 5 \% \mathrm{RH}$ and $40 \pm 2^{\circ} \mathrm{C} / 75 \pm 5 \% \mathrm{RH}$ respectively. The tested formulation was inspected visually after the period of three months. No change in color was found, gel homogeneity was maintained and there was no recrystallization of the gel occurred. $\mathrm{pH}$ of the fresh gel formulation was $6.88 \pm 0.07$ and after 3 months of storage slight decrease in the $\mathrm{pH}$ value was observed i.e, $6.05 \pm 0.12$, this can be attributed to proximity of drug and polymer over a long period. Also a slight reduction in the viscosity of the gel formulation was observed after the storage of 3 months. A very minimal reduction in the drug release was observed over a period of 90 days in both room and accelerated temperature. Hence, it can be concluded that the optimized gel formulation, GF-1, exhibited acceptable stability profile at room temperature $\left(25 \pm 2^{\circ} \mathrm{C} / 60 \pm 5 \%\right.$ $\mathrm{RH})$ and accelerated temperature $\left(40^{\circ} \mathrm{C} / 75 \% \mathrm{RH}\right)$ for a defined period of three months.

\section{DISCUSSION}

In the present study solid dispersions of Fluconazole was prepared to enhance its aqueous solubility. On comparison of two different methods of preparation of solid dispersion i.e. Solvent evaporation and hot melt method, it was found that solid dispersions formulated by Solvent evaporation method showed enhanced aqueous solubility and better dissolution rate. Also solid dispersion formulated using $\beta$-cyclodextrin showed better results when compared with PVP.

All the three Fluconazole solid dispersion incorporated Aloe-vera gel formulations were translucent and their $\mathrm{pH}$, drug content, extrudability and viscosity were found in the acceptable range. The optimized gel formulation, GF1, was then tested for antifungal activity and was compared with marketed formulation for the same. The tested formulation was found to exhibit better anti-fungal activity than the marketed formulation. This may be due to the presence of Aloe-vera gel which also exhibits antifungal activity and so, may results in 
the enhanced antifungal activity of the prepared gel formulation. ${ }^{29-31}$ In vitro release kinetic data was best fits in korsmeyer-peppas model showing non-fickian drug release mechanism i.e, the release mechanism of drug from formulation is both by diffusion and by swelling of the polymer. ${ }^{32}$ The optimized formulation remains stable under the accelerated conditions even after duration of three months.

\section{CONCLUSION}

On the basis of above findings, it can be concluded that Fluconazole solid dispersions are successfully incorporated into the Aloe vera gel using $\beta$-cyclodextrin as the complexing agent. Among the two method used for the solid dispersion formulation, Solvent evaporation method was found to be the best method, as the formulations showed better aqueous solubility and enhanced dissolution rate when compared with the other method. Among 12 solid dispersion formulations, F3 showed the best results and so was incorporated into the Aloe vera gel formulation. The formulated gel showed enhanced diffusion rate and better antifungal activity than the marketed formulation. Thus, it can be concluded that our formulae could be very promising topical alternative for the treatment of skin fungal infections. Pre-clinical and clinical studies need to be carried out in future.

\section{ACKNOWLEDGEMENT}

We sincerely express our thanks to GRD (PG) IMT, Dehradun, Uttarakhand for providing us wonderful work environment and also the sophisticated equipment and facilities. We also acknowledge SGGR University, Dehradun for providing their laboratory facilities.

\section{CONFLICT OF INTEREST}

All authors hereby unanimously declared that there is no conflict of any financial interest.

\section{ABBREVIATIONS}

PVP: Polyvinyl pyrrolidine; CD: Cyclodextrins; FTIR: Fourier-transform infra-red spectroscopy; cPs: Centi-poise; GF: Gel Formulation.

\section{REFERENCES}

1. AHFS Drug Information. 2003;90.

2. Andriole VT. Current and future antifungal therapy: New targets for antifungal agents. J Antimicrob Chemother. 1999;44(2):151-62.
3. Chauhan CS, Sisodiya DS. Formulation and evaluation of fluconazole solid dispersion incorporated gel-using polymers as controlled release dosage forms: Development, characterization and in vitro evaluation. International Bulletin of Drug Research. 2013;3(4):1-10.

4. El-Housiny S, Maii ASE, et al. Fluconazole-loaded solid lipid nanoparticles topical gel for treatment of pityriasis versicolor: Formulation and clinical study. Drug Delivery. 2018;25(1):78-90.

5. Papageorgiou GZ, Bikiaris D, et al. Tailoring the Release Rates of Fluconazole using Solid Dispersions in Polymer Blends. Drug Development and Industrial Pharmacy. 2008;34(3):336- 46

6. Shukla V, Masareddy R, Anghore A, Manvi FV. Influence of $\beta$-Cyclodextrin Complexation on Ketoprofen Release from Matrix Formulation. Int $\mathrm{J}$ Pharm Sci Drug Res. 2009;1(3):195-202.

7. Gaurav T, Ruchi T, Awani KRA. Cyclodextrins in delivery systems: Applications. J Pharm Bioallied Sci. 2010;2(2):72-9.

8. Shirse P, Rao SK, Iqbal MM. Formulation and evaluation of cyclodextrin inclusion complex tablets of water insoluble drug-Glimipiride. Int J Res Pharm Chem. 2012;2(1):222-30.

9. Renisheya JJMT, Johnson M, Nancy BS, Laju RS, Anupriya G, Renola JJET. Anti-bacterial and antifungal activity of Aloe vera gel extract. Int J Biomed Adv Res. 2012;3(3):184-7.

10. Grindlay D, Reynolds T. The Aloe vera phenomenon: A review of the properties and modern uses of the leaf parenchyma gel. J Ethnopharmacol. 1986;16(2-3):117-51.

11. Vogler BK, Ernst E. Aloe vera: A systematic review of its clinical effectiveness. Br J Gen Pract. 1999;49(447):823-8.

12. Grace OM, Simmonds MS, Smith GF, WykAE. Therapeutic uses of Aloe vera L. (Asphodelaceae) in southern Africa. J Ethnopharmacol. 2008;119(3):604-14.

13. Eshun K, Qian H. Aloe vera: A Valuable Ingredient for the Food, Pharmaceutical and Cosmetic Industries: A Review. Crit Rev Food Sci Nutr. 2004;44(2):91-6.

14. Abdul WK, Sabna K, Shahid HA, Rakesh KS, Amit K, Javed A. Formulation development, optimization and evaluation of Aloe vera gel for wound healing. Pharmacogn Mag. 2013;9(Suppl 1):S6.

15. Maryam A, Zahra S, Behjat J, Amirhossein S, Seyed AE. Therapeutic effects of Aloe spp. in traditional and modern medicine: A review. Biomedicine and Pharmacotherapy. 2016;84:759-72.

16. Jeyasakthy S, Rosdan S, Irfan M, Azian H. Antifungal Effect of Malaysian Aloe vera Leaf Extract on Selected Fungal Species of Pathogenic Otomycosis Species in in vitro Culture Medium. Oman Medical Journal. 2017;32(1):41-6.

17. Kumar S, Yadav M, Yadav JP. Comparative analysis of antimicrobial activity of methanolic extracts of Aloe vera and quantification of Aloe Emodin collected from different climatic zones of India. AC Microb. 2015;6(2):1.

18. Shekh I, Gupta V, Jain A, Gupta N. Preparation and Characterization of B-cyclodextrin Aspirin Inclusion Complex. Int J Pharm Life Sci. 2011;2(4):704-10.

19. Vaibhav S, Roshan T. Formulation and Evaluation of Tooth Gel from Aloe vera leaves extract. Int J Pharm Drug Anal. 2017;5(10):394-8.

20. Basha BN, Prakasam K, Goli D. Formulation and Evaluation of Gel containing Fluconazole-Antifungal Agent. Int J Drug Dev Res. 2011;3(4):109-28.

21. Davis ME, Brewster ME. Cyclodextrin-based pharmaceutics: past, present and future. Nat Rev Drug Discov. 2004;3(12):1023-35.

22. Sharma N, Baldi A. Exploring versatile applications of cyclodextrins: An overview. Drug Delivery. 2016;23(3):729-47.

23. Loftsson T, Brewster ME. Pharmaceutical applications of cyclodextrins: Basic science and product development. J Pharm Pharmacol. 2010;62(11):1607-21.

24. Rasheed A, Kumar ACK, Sravanthi VVNSS. Cyclodextrins as drug carrier molecule: A review. Sci Pharm. 2008;76(4):567-98.

25. Lin $\mathrm{SH}, \mathrm{Kao} \mathrm{YH}$. Solid particles of drug- $\beta$ cyclodextrin inclusion complexes directly prepared by a spray-drying technique. Int J Pharm. 1989;56(3):249-59.

26. Gülsel Y, Müzeyyen D, Lütfi G. Inclusion complexes of fluconazole with b-cyclodextrin: physicochemical characterization and in vitro evaluation of its formulation. J Incl Phenom Macrocycl Chem. 2011;70(3-4):429-35.

27. Jain SBD, Padsalg A, Patel K, Mokale V. Formulation development and evaluation of fluconazole gel in various polymer Bases. Asian Journal of Pharmaceutics. 2007;1(1):63-8. 
28. Mekkawy A, Fathy M, Shanawany SE. Formulation and in vitro Evaluation of Fluconazole Topical Gels. British Journal of Pharmaceutical Research. 2013;3(3):293-313.

29. Kumar VPPN, Shameem U, Kollu PRL, Kalyani SVNP. Green Synthesis of Copper Oxide Nanoparticles using Aloe vera Leaf Extract and Its Antibacterial Activity against Fish Bacterial Pathogens. Bio Nano Science. 2015;5(3):1359.

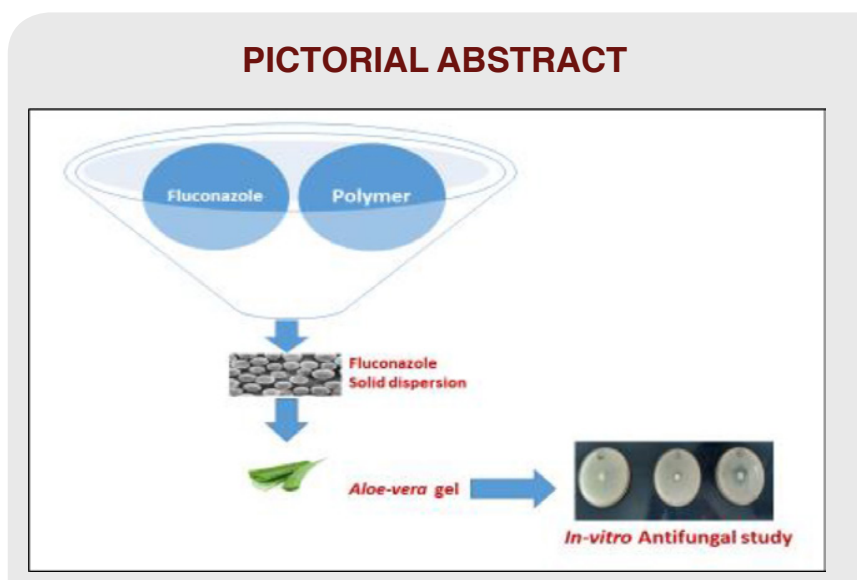

30. Rezazadeh F, Moshaverinia M, Motamedifar M, Alyaseri M. Assessment of Anti HSV-1 Activity of Aloe vera Gel Extract: an in vitro Study. J Dent. 2016;17(1):49-54.

31. Mahor G, Ali SA. Recent update on the medicinal properties and use of Aloe vera. Biosci Biotech Res Comm. 2016;9(2):273-88.

32. Paarakh MP, Jose PA, Setty CM, Christoper GVP. Release kinetics- Concepts and Applications. Int J Pharm Res Tech. 2018;8(1):12-20.

\section{About Authors}

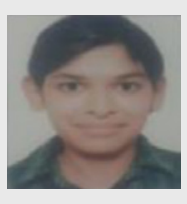

Mrs. Tanuja Bisht M.Pharm Pharmaceutics (Gold Medal), KLE University, Belagavi, Karnataka. More than five years of teaching experience.

Cite this article: Aswal D, Bisht T. Transdermal Delivery of Fluconazole ß-cyclodextrin Complex Incorporated in Aloe vera Gel for Fungal Therapy: Development, Characterization and in vitro Evaluation. Indian J of Pharmaceutical Education and Research. 2021;55(1s):s66-s74. 